\title{
Epidurual pneumatosis: a benign complication of benign pneumomediastinum
}

\author{
C. Defouilloy*, C. Galy*, E. Lobjoie*, V. Strunski**, M. Ossart*
}

Epidurual pneumatosis: a benign complication of benign pneumomediastinum. C. Defouilloy, C. Galy, E. Lobjoie, V. Strunski, M. Ossart. @ERS Journals Ltd 1995. ABSTRACT: Subcutaneous emphysema and pneumomediastinum are well-known complications of barotrauma. There are no fascial barriers between the posterior mediastinum and the retropharyngeal and epidural spaces; thus, air can diffuse freely to the epidural space and produce an epidural pneumatosis.

We report a case of epidural pneumatosis caused by a pneumomediastinum following nasotracheal intubation for an attempted suicide. This benign complication of air leakage was easily recognized on computed tomography (CT) scan. Eur Respir J., 1995, 8, 1806-1807.
* Service de Réanimation Polyvalente, CHU Nord, Amiens, France. **Service d'OtoRhino-Laryngologie, CHU Nord, Amiens, France.

Correspondence: C. Defouilloy, CHU Nord Place Victor Pauchet

80054 Amiens Cedex 1 France

Keywords: epidural pneumatosis, pneumomediastinum

Received: March 201995

Accepted after revision May 191995

\section{Case report}

A 22 year old man was hospitalized in the Intensive Care Unit (ICU) for a pneumomediastinum with a conspicuous subcutaneous emphysema. Five years earlier, the patient had been treated for a severe ulcerated and necrotized subglottic laryngitis, which was considered to be cured 15 days later.

Four days before his admission to our unit, the patient had been hospitalized in another unit because of attmpted suicide with benzodiazepine and alcohol. Flumazenil produced an incomplete awaking. A nasotracheal intubation (7.5 mm internal diameter (ID)) was necessary, and was performed under thiopental and vecuronium. During intubation, the physician perceived tracheal rings.

During the awakening period, the patient made many efforts to cough. Extubation was performed $24 \mathrm{~h}$ later.

A subcutaneous emphysema was apparent the next day, with a pneumomediastinum. Two days later, this subcutaneous emphysema had increased and a slight pneumothorax had developed. The patient was then transferred to our ICU.

On addmission, the patient was conscious (coma Glasgow score $=15)$, with a simplified acute physiological score (SAPS) $=5$ and without fever $\left(37^{\circ} 2 \mathrm{C}\right)$. Clinical examination showed widespread subcutaneous emphysema involving the chest and neck, dysphonia and "laryngeal dyspnoa". A neurological examination was normal. Blood gases (with $6 \mathrm{~L} \cdot \mathrm{min}^{-1}$ of oxygen delivered by nasal prongs) were: arterial oxygen tension $\left(\mathrm{Pa}_{\mathrm{a}} \mathrm{O}_{2}\right) 13.2 \mathrm{kPa}$; $\left(P \mathrm{a}, \mathrm{CO}_{2}\right): 6.4 \mathrm{kPa}$; $\mathrm{pH} 7.35$; lactic acid $3.11 \mathrm{mmol} \cdot \mathrm{L}^{-1}$.

Chest radiography showed a pneumomediastinum and a partial pneumothorax of the left apex. A flexible bronchoscopy was performed: the larynx was normal but the tracheal mucosa was stripped just below the cricoid cartilage, and the stenosis could not be passed through.
Oesophagogastric examination excluded oesophageal rupture.

Neck and thorax CT scan was performed to evaluate the extent of the stripping, which was shown to involve the first $5 \mathrm{~cm}$ of the trachea, pneumomediastinum and pneumothorax. Air had dissected all structures of the neck and had collected in the spinal canal and around the vertebral artery (figs 1 and 2). In the dorsal spinal canal, air extended as far as the D3 vertebral body.

Because of respiratory muscle fatigue, a tracheotomy was performed below the inferior border of the stenosis. The tracheobronchial tree was then explored and no abnormality was detected. The patient's status was improving spontaneously and 15 days later the tracheotomy was closed. During this time, we could observe the progressive reabsorption of the pneumomediastinum and subcutaneous emphysema.

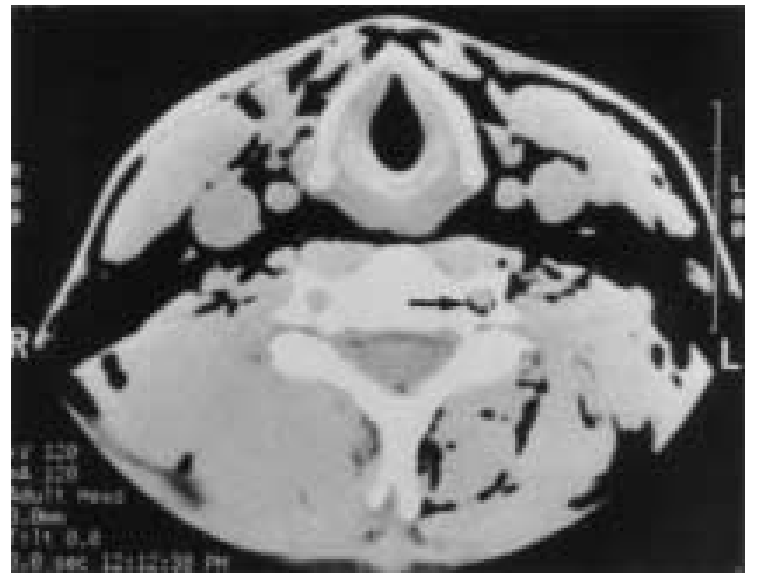

Fig. 1. - Computed tomography (CT) scan image of the neck (C6 level) showing cervical emphysema with the air around vertebral artery (arrow). 


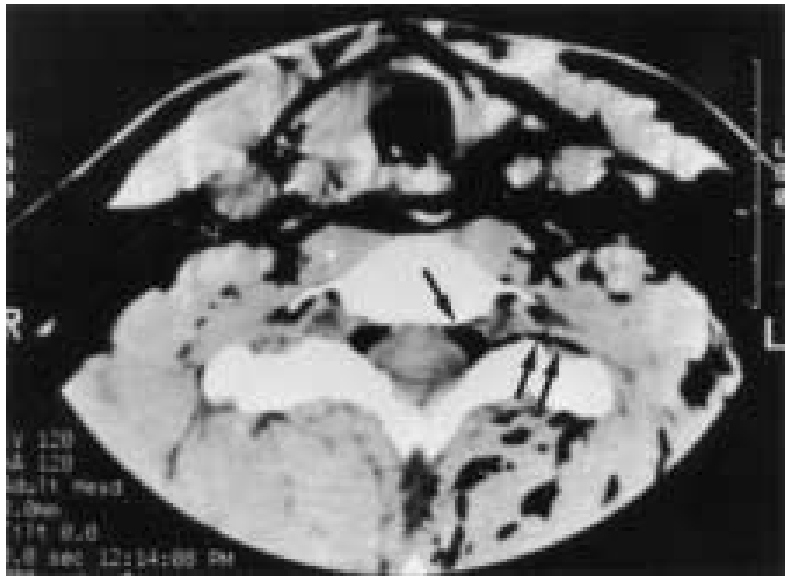

Fig. 2. - Computed tomography (CT) scan image (D1 level) showing the air collection in the epidural space (single arrow). On the left, the pathway of air dissection leading to epidural pneumatosis via the neural foramina is well seen (two arrows).

\section{Discussion}

Epidural pneumatosis, also called pneumorrhachis or aerorachia, accounts for the visualization of air in the spinal epidural space. A variety of factors can give rise to this condition: epidural abcess, trauma of the skull [1, 2] or of the spine [3], epidural anaesthesia, or unsuccessful lumbar puncture and pneumomediastinum [4-6].

A possible explanatory mechanism for pneumomediastinum is high bronchoalveolar pressure during cough resulting in air leakage into pulmonary perivascular interstitium. The air dissects the paths of least resistance into the mediastinum to the fascial planes of the neck.
There are no fascial barriers to prevent communication of the posterior mediastinum or retropharyngeal space with the epidural space. Air can thus communicate freely via the neural foramina [6] (fig. 2).

In this case, the previous anterior laryngitis probably explains the weakness of the tracheal mucosa and its stripping. The existence of a scar stenosis can also be presumed.

This report leads to two conclusions: firstly, intubation is not always a procedure without consequences, and secondly, epidural pneumatosis is a benign complication of pneumomediastinum, easily visible by CT scan.

\section{References}

1. Prins TR, Vencken LM. Traumatic pneumosaccus. Neuroradiology 1989; 31: 290.

2. Newbold RG, Wiener MD, Vogler JB, Martinez S. Traumatic pneumorrhachis. Am J Roentgenol 1987; 148: 615-616.

3. Silver SF, Madel HR, Foldmark O. Pneumorrhachis after jejunal entrapment caused by a fracture dislocation of the lumbar spine. Am J Roentgenol 1988; 150: 11291130.

4. Willing SJ. Epidural pneumatosis: a benign entity in trauma patients. AJNR 1991; 12: 345.

5. De Meulder A, Michaux L. Aerorachia. Intens Care Med 1990; 16: 275-276.

6. Balachandran S, Guinto C, Goodman P. Epidural pneumatosis associated with spontaneous pneumomediastinum. AJNR 1993; 14: 271-272.

7. Place JN, Pezzuti RT. Clinical significance of traumatic pneumorrhachis. Am J Roentgenol 1989; 153: 655. 